\title{
Konsep Maqashid Syariah Menurut Al-Syatibi Dan Kontribusinya Dalam Kebijakan Fiskal
}

\author{
Nabila Zatadini \\ Pascasarjana Universitas Darussalam Gontor \\ Email:zatadini.nabila@gmail.com

\section{Syamsuri} \\ Pascasarjana Universitas Darussalam Gontor \\ Email:syamsuri@unida.gontor.ac.id
}

\begin{abstract}
Economic inequality is a common problem for all people in the world. To overcome this inequality government intervention is needed through fiscal policy. Successful fiscal policy took place during the Caliphate Umar bin Abdul Aziz who used maqashid sharia as its foundation. One Muslim scholar who has deep thoughts about maqashid sharia and contributes to the economy is Imam alSyatibi. For this reason, research is needed on Maqashid Shari'ah and its contribution to fiscal policy. This paper aims to examine al-Syatibi's thought about maqashid syari'ah followed by its contribution to fiscal policy. The results of this study are maqashid sharia according to al-Syatibi aimed at maslabah which is classified into three dimensions: primary, secondary, and complementary. Maqashid Shari'ah has a big contribution in three aspects of fiscal policy, namely state expenditure, tax collection and household costs.
\end{abstract}

Keywords: Maqashid Shariah; al-Syatibi; Fiscal Policy, Inequality, and Common Problem

\begin{abstract}
Abstrak
Ketimpangan ekonomi menjadi masalah umum bagi seluruh masyarakat di dunia. Untuk mengatasi ketimpangan tersebut dibutubkan intervensi pemerintah melalui kebijakan fiskal. Kebijakan fiskal sukses terjadi pada masa khilafah Umar bin Abdul Azizyang menggunakan maqashid syariah sebagai landasannya. Salah satu ulama muslim yang memiliki pemikiran mendalam mengenai maqashid syariah dan berkonstribusi dalam ekonomi adalah Imam alSyatibi. Untuk itu diperlukan adanya penelitian mengenai maqashid syari'ah dan kontribusinya dalam kebijakan fiskal. Paper ini bertujuan untuk mengkaji pemikiran al-syatibi tentang maqashid syariah dilanjutkan dengan kontribusinya dalam kebijakan fiskal. Hasil dari penelitian ini adalab maqashid syariah menurut al-Syatibi bertujuan maslahah yang terklasifikasi menjadi tiga dimensi: primer, sekunder, dan pelengkap. Maqashid syari'ah memiliki andil besar dalam tiga aspek kebijakan fiskal yaitu belanja negara, pemungutan pajak dan biaya rumah tangga.
\end{abstract}

Kata Kunci: Maqashid Syariah; Al-Syatibi; Kebijakan Fiskal, Ketimpangan dan Masalah Umum

Al Falah: Journal of Islamic Economics, Vol. 3, No. 2, 2018

STAIN Curup|E-ISSN: 2548-3102, P-ISSN: 2548-2343

Available online: http://journal.staincurup.ac.id/index.php/alfalah 


\section{PENDAHULUAN}

Masalah ekonomi 'kemiskinan' masih belum terselesaikan hingga saat ini meskipun sudah sangat amat banyak cara, program yang dilaksanakan namun program tersebut masih saja belum membuahkan hasil yang berarti. Dunia ini masih dihantui dengan ketimpangan ekonomi, baik antar Negara maupun antar individu. Seperti republic afrika timur yang memiliki GDP perkapita sebesar 325.70 USD di bulan Desember lalu, sedangkan Qatar memiliki GDP perkapita sebesar 66.415.30 USD. ${ }^{1}$ Data tersebut menjelaskan betapa jauhnya ketimpangan ekonomi yang terjadi di dunia ini.

Untuk mengatasi ketimpangan tersebut dibutuhkan adanya intervensi pemerintah. Salah satu bentuk intervensi pemerintah adalah kebijakan fiskal. Untuk mencapai kesuksesan kebijakan fiskal diperlukan adanya analisa kesuksesan Khalifah Umar bin Abdul Aziz dalam memimpin negaranya. Pada masanya, tidak terjadi ketimpangan ekonomi, bahkan penyalur zakat bingung akan menyalurkan zakat kemana karena asnaf penerima zakat hampir punah. Selain itu pembangunan infrastruktur pada masanya sangat berkembang pesat dan tidak ditemukan lingkungan kotor yang menimbulkan penyakit. ${ }^{2}$

Jika ditelaah terlihat bahwa rahasia Umar bin Abdul Aziz adalah kebijakan yang berlandaskan maqashid syariah. Maqashid syari'ah sangat penting dalam ekonomi Islam dan menduduki tempat yang amat penting dalam menentukan hukum. Banyak hal baru yang muncul dan belum tertera dalam fiqh. Hal tersebut menjadikan maqashid sebagai jalan utama untuk menentukan hukum. Diperlukan kriteria dan standar agar bisa menentukan maqashid hingga terbebas dari hawa nafsu dan kepentingan dunia semata. ${ }^{3}$

Standar dan kriteria penentuan maqashid telah dibahas oleh berbagai ulama klasik, salah satunya Imam al-Syatibi. Al-Syatibi membangun standar dan kriteria penentuan maqashid dengan membagi tiga bagian utama, yaitu: masalah ta"lil, dan al-mashâlì wa al-mafâsid. Kedua, terkait dengan cara untuk mengetahui maqâshid. Ketiga, operasionalisasi ijtihad al-maqâsyid. Al-Syatibi juga berpendapat bahwa maqashid syariah bertujuan maslahah. ${ }^{4}$ Maslahah memiliki peran penting untuk membangun sistem ekonomi yang holistic. Nilai-nilai maslahah yang

1 Lihat di https://id.tradingeconomics.com/country-list/gdp-per-capita, Diakses pada 10/10/2018. Pukul 10:30 wib.

${ }^{2}$ Radieah Mohd Nor, "Success Factors for Baitul mal Management during the Reign of Caliph Umar ibn Abdul Aziz”, Open Journal of Social Sciences, Vol.03 No.05(2015), 1-2.

3 Aminah, "Maqāṣid Asy-Syarī'Ah Pengertian Dan Penerapan Dalam Ekonomi Islam", Fitrah Jurnal Kajian Ilmu-ilmu Keislaman, Vol. 03 No. 1 Juni 2017, 182

${ }^{4}$ Moh. Toriquddin, "Teori Maqâshid Syarî’ah Perspektif Al-Syatibi", De Jure, Jurnal Syariah dan Hukum, Volume 6 Nomor 1, Juni 2014, 47 
dikenalkan oleh al-Syatibi akan membawa ekonomi Islam kepada ekonomi yang holistic. Implementasi maslahah dapat dilakukan dalam konsep pemenuhan kebutuhan manusia, paradigma aktifitas ekonomi, dan standar utility dalam memenuhi kebutuhan barang dan jasa. ${ }^{5}$

Untuk mengetahui implementasi nilai-nilai maslahah yang diajukan alSyatibi, diperlukan adanya pembahasan. Pembahasan yang terfokus dengan kontribusi maqashid syari'ah dalam kebijakan fiskal guna menyelesaikan masalah ketimpangan ekonomi. Mengingat al-Syatibi merupakan ulama yang terkenal dengan konsep maqashid syari'ah-nya.

Metode yang digunakan dalam penelitian ini yaitu penelitian kepustakaan. ${ }^{6}$ Data dikumpulkan dengan menggunakan metode dokumenter, yang bersumber dari buku, jurnal, internet, dan makalah tentang pemikiran alSyatibi mengenai maqashid syariah dan kebijakan fiskal. Metode analisis data yang digunakan adalah induktif, deduktif, dan analisis deskriptif.

\section{HASIL DAN PEMBAHASAN}

\section{Biografi Imam al-Syatibi}

Imam Al-Syatibi bernama lengkap Ibrahim bin Musa bin Muhammad Al-Lakhimy Al-Gharnathy Abu Ishaq. ${ }^{7}$ Tidak banyak referensi yang menjelaskan biografi tentangnya. Orang pertama yang menulis biografi beliau adalah Ahmad Baba yang hidup 200 tahun setelah Al-Syatibi. ${ }^{8}$ Maka, keterangan mengenai hidup beliau tidak terlalu banyak. Beliau merupakan seorang hafidz qur'an, mujtahid, ahli ushuliyah, tafsir, fiqh, hadits, dan Bahasa.

Dinisbahkan dari jukukannya, Imam Al-Syatibi lahir di Syatiba, dan kemudian tumbuh besar di Gharnathah atau Granada. ${ }^{10}$ Granada pada saat itu menjadi pusat keilmuan. Orang-orang Afrika Utara berbondong-bondong ke sana untuk menuntut ilmu. Granada menjadi ibu kota kerajaan Nasri yang dipimpin oleh Sultan Muhammad V al-Gani Bilah, pemimpin masa kejayaan

${ }^{5}$ Muslimin Kara, "Pemikiran Al-Syatibi Tentang Maslahah Dan Implementasinya Dalam Pengembangan Ekonomi Syariah”, Assets Volume 2 Nomor 2 Tahun 2012, 183

${ }^{6}$ Sugiono, Metode Penelitian Kuantitatif, Kualitatif Dan R \& D, (Bandung: Alfabeta, 2014), 240

7 Ahmad Baba al-Tanbakti, Nailu al-Ibtihaj bi Tatbridzi al-Dibaj, (Tripoli: Daar al-Katib, 2000), 48

${ }^{8}$ M. Khalid Mas'ud, “Abu Ishaq Shatibi: His Life and Works”, Islamic Studies Vol. 14, No. 2 (Summer 1975), h. 145-161, 145

${ }^{9}$ Ahmad Baba al-Tanbakti, Nailu al-Ibtihaj bi Tathridzi al-Dibaj, 48

${ }^{10}$ Imron Rosyadi, "Pemikiran Asy-Syatibi Tentang Maslahah Mursalah", Profetika, Jurnal Studi Islam, Vol. 14, No. 1, Juni 2013: 79-89, 79 
Granada. Salah satu ulama yang belajar di Granada adalah ibnu Khaldun dan Ibnu Khatib. ${ }^{11}$

Pendidikan pertama yang didapat oleh Syatibi adalah pelajaran Bahasa Arab. Guru pertamanya dalam pelajaran Bahasa Arab dan Nahwu adalah Abu Abdullah Muhammad Al-Biri yang terkenal sebagai master Nahwu (Syaikh alNuhat) di Andalus hingga ia meninggal pada tahun 754 H/1353 M. Kemudian Syatibi melanjutkan belajar Bahasa Arab dan Nahwu kepada Abul Qasim alSharif al-Sibti yang memiliki julukan 'pemegang standar retorika' dalam Bahasa Arab, selain itu al-Sibti diberi julukuan sebagai 'rais al-Ulum al-Lisaniyah' atau raja linguistic. Syatibi belajar kepadanya hingga al-Sibti meninggal pada tahun 760 $\mathrm{H} / 1358 \mathrm{M}^{12}$

Setelah mengenyam pendidikan mengenai Bahasa Arab, Syatibi melanjutkan studinya mempelajari fiqh. Ia mempelajari fiqh di Granada dari seorang mufti dan khatib yaitu Abu Sa'id bin Lubb. Syatibi menguasai figh berkat ajaran Lubb, meskipun mereka memiliki ide yang bertentangan mengenai beberapa masalah fiqh. Tidak hanya kepada tiga guru tersebut, Syatibi belajar ke guru-guru lain di Granada. Seperti, Abu Abdullah al-Maqarri, Abu Ja'far alSyaqwari, Abu al-Abbas al-Qubab, Abu Abdullah al-Hufaz, dan lain-lain. ${ }^{13}$ Dari segenap guru Syatibi, yang memiliki pengaruh besar terhadap keilmuan Syatibi adalah Abu Abdullah al-Maqarri.

Abu Abdullah al-Maqarri merupakan seorang qadhi atau hakim ternama di Fez. Kemudian Maqarri diutus menjadi diplomat oleh Sultan Abu Inan dan dikirim ke Granada. Saat di Granada ia ditangkap dan dipulangkan ke Fez. Kepulangannya diantar oleh Abu al-Qasim al-Sabti dan Abu al-Barakat bin alHajj al-Balfiqi qadhi di Granada. Mereka mengantar Maqarri sampai ke Fez guna memastikan keselamatannya. Maqarri adalah penulis buku Nahwu dan ia mendapat derajat mubaqqiq atau seseorang yang sangat ahli dalam madzhab Maliki di bidang fiqh. Selain itu, Maqarri menulis buku tasawwuf, dan ushul fiqh. Maqarri adalah ulama yang membawa syatibi ke dalam dunia sufi. ${ }^{14}$

Syatibi juga mempelajari ilmu rasional atau ulum al-aqliyyah. Ia mempelajarinya dari dua ilmuwan besar Abu Ali Mansur al-Zawawi dan Abu Abdulllah al-Sharif al-Tilmisani. ${ }^{15}$ Zawawi tinggal di Granada pada tahun $753 \mathrm{H}$ $765 \mathrm{H}$, ia merupakan ulama yang amat berpengaruh dalam bidang filosofi dan

${ }^{11}$ M. Khalid Mas'ud, "Abu Ishaq Shatibi: His Life and Works”, 147

${ }^{12}$ M. Khalid Mas'ud, "Abu Ishaq Shatibi: His Life and Works, .....

${ }_{13}$ Ahmad Baba al-Tanbakti, Nailu al-Ibtibaj bi Tatbridzi al-Dibaj, 49

${ }^{14}$ M. Khalid Mas'ud, "Abu Ishaq Shatibi: His Life and Works", 148

15 Muhammad Mawardi Djalaluddin, "Pemikiran Abu Ishaq Al-Syatibi dalam Kitab AlMuwafaqat", Al Daulab Vol. 4 / No. 2 / Desember 2015, h. 289-300, 293 
teologi. Sedangkan Tilmisani terkenal sebagai 'al-Imam al-Mubaqqiq A'lamu Abli Waqtihi atau orang yang paling berilmu pada masanya. Ia penulis buku Miftah alUsul ila Bina al-Furu' 'ala al-Usul, sebuah maha karya dalam ilmu ushul fiqh. ${ }^{16}$

Adapun murid yang belajar dari Syatibi hanya diketahui tiga orang dari keseluruhan. Dua bersaudara Imam ternama yaitu Abu Yahya bin 'Asim dan Abu Bakar bin 'Asim. Abu Bakar adalah ketua qadhi atau hakim di Granada dan terkenal dengan karyanya Tuhfat al-Hukkam, kumpulan undang-undang yang digunakan oleh hakim di Granada. Muridnya yang ketiga adalah Abu Abdullah al-Bayani. ${ }^{17}$

Selama hidupnya al-Syatibi menghasilkan beberapa karya tulis. Pertama, Al-Khulashah fi al-Nahwi fi Asfari Arba'ati Kibar yaitu buku yang menjelaskan komentar-komentar Syatibi mengenai buku al-Khulasa al-Alfiyyah karangan Ibnu Malik. Kedua, Al-Muwafaqat, maha karya Syatibi yang paling utama. Buku yang menjelaskan mengenai ilmu ushul fiqh dan pengenalan terhadap konsep maslahah dan maqashid menurut Syatibi. Ketiga, Kitab al-Majalis, buku yang menjelaskan bab jual beli dalam kitab sahib bukhari. Keempat, Kitab al-Ifadat wa al-Insyadat, menjelaskan sastra dan seni mengarang dalam Bahasa Arab. Kelima, Kitab Unwan al-Ittifaq fi Tlmi al-Isytiqaq. Keenam, Kitab Ushul al-Nabwi. Selain itu Syatibi menciptakan berbagai fatwa dan juga syair-syair Arab. ${ }^{18}$

\section{Konsep Maqashid Syariah Menurut al-Syatibi}

Sebelum memahami maqashid syariah, akan dijelaskan terlebih dahulu pengertian maqashid syariah. Maqashid shariah secara harfiah berarti tujuan hukum. Maqashid, dari kata qashada yang berarti tujuan. Tujuan atau hasilnya yang diharapkan dari perundang-undangan undang-undang. ${ }^{19}$ Maqasid alSyari'ah telah secara langsung disebutkan dalam Al-Qur'an dan Sunnah atau disimpulkan dari ini oleh sejumlah ilmuwan. Semua hal ini mengatakan urgensi pemenuhan maslahah (jalb al-masalih) dari semua manusia dan untuk menyelamatkan mereka dari bahaya (daf'u al-mafasid / dar'u al-mafasid).

Secara terminologi, maqashid berarti makna-makna dan hikmah-hikmah dan sejenisnya yang dikehendaki Tuhan dalam tiap syariat baik umum maupun khusus, guna memastikan maslahat hamba-Nya. Maksud dari 'makna' di sini adalah sebab, maksud dan sifat. 'Hikmah' berarti sifat, sifat syariat Islam yaitu

${ }^{16}$ Imam al-Shatibi: The Master Architect of Maqasid, http://www.iais.org.my/e/attach/Imam_al-Shatibi.pdf, diakses pada tanggal 25 Juli 2018, 11.41 WIB, 2

${ }^{17}$ Ahmad Baba al-Tanbakti, Nailu al-Ibtihaj bi Tatbridri al-Dibaj, 50

${ }^{18}$ Imam al-Shatibi: The Master Architect of Maqasid, h. 3-4

${ }^{19}$ Kamil Iskandar, Al-Munjid Al Wasith, (Beirut:Daar al-Masyriq), 855 
mendapatkan mahlahah. 'Dikehendaki tuhan dalam tiap syariat' dimaksudkan bahwa tuhan menginginkan dalam syariat-Nya. Arti dari 'baik umum dan khusus' adalah mencakup syariat umum yang berisi tentang dalil-dalil syariah dan khusus berisi hukum-hukum. Sedangkan makna dari 'guna memastikan maslahat hamba-Nya' adalah bahwa apa yang yang disyariatkan Tuhan tidak lain untuk maslahat hamba-Nya di dunia dan akhirat. ${ }^{20}$

Al-Syatibi tidak menjelaskan definisi maqashid syariah dalam bukunya, ia langsung menjelaskan detil isi maqashid syariah dari pembagiannnya. Syatibi membagi maqashid menjadi dua, qashdu al-syari' (tujuan Tuhan) dan qashdu almukallaf ${ }^{1}$ (tujuan mukallaf). Kemudian ia membagi qashdu syari' menjadi empat macam. Pertama, qashdu al-syari' fi wadh'i al-syari'ah; kedua, qashdu al-syari' fi wadh'i al-syariah li al-ifham; ketiga, qashdu al-syari' fi wadh'i al-syari'ah li al-taklif bi muqtadhaha; keempat, qashdu al-syari' fi dukhuli al-mukallaf tabta abkami al-syari'ah. Sedangkan bagian qashdu al-mukallaf, Syatibi tidak menyebutkan macammacamnya. ${ }^{22}$

Selanjutnya akan dijelaskan macam-macam dari qashdu al-syari' satu persatu. Macam pertama adalah qashdu al-syari' fi wadh'i al-syari'ah (tujuan Tuhan meletakkan syariah). Maksud Allah menetapkan syariah tidak lain guna kepentingan maslahah hamba-Nya. Syatibi membagi maslahah tersebut menjadi tiga derajat beurutan dari kebutuhan manusia dari padanya, yaitu: dharuriyyah, hajjiyyah, dan tahsiniyyah. Dharuriyyah memegang derajat maslahah tertinggi karena manusia tidak dapat hidup tanpanya. Jika seseorang tidak terpenuhi maslahah dharuriyyah-nya, maka akan terjadi kerusakan di dunia dan akhirat. Kadar kerusakan sesuai dengan maslahah dharuriyyah yang hilang. ${ }^{23}$ Maslahah dharuriyyah dilakukan dengan menjaga agama, diri, nasab, harta, dan akal. Contoh dari menjaga agama ialah mendirikan rukun iman dan Islam. ${ }^{24}$

Maslahah setelah dharuriyyah adalah maslahah bajiyyah. Masalahah hajjiyyah merupakan masalahah yang bersifat memudahkan, menghindarkan manusia dari kesulitan dan kesusahan. Namun, ketiadaan maslahah hajjiyyah tidak menyebabkan kerusakan di dunia maupun akhirat. ${ }^{25}$ Contoh dari maslahah

${ }^{20}$ Muhammad Saad bin Ahmad bin Mas'ud al-Yubi, Maqashidu al-Syariah al-Islamiyah wa 'Alaqatuha bi al-Adillati al-Syariyyah, (Riyadh: Daar al-Hijrah, 1998), 37-38

${ }^{21}$ Mukallaf berarti dibebani. Maksud dibebani di sini adalah bahwa tiap orang memegang kewajiban yang harus dipertanggungjawabkan, paling tidak berkewajiban atas dirinya

22 Abu Ishaq al-Syatibi, al-Muwafaqat fi Ushuli al-Syariah, (Beirut: Dar Al-Kotob AlIlmiyah, 2004), 219

23 Ahmad Raysuni, Nadhariyyatu al-Maqashidi Inda al-Imam al-Syatibi, (Virginia: IIIT, 1995), $145-146$

${ }^{24}$ Abu Ishaq al-Syatibi, al-Muwafaqat fi Ushuli al-Syariah, 221

25 Ahmad Raysuni, Nadhariyyatu al-Maqashidi 'Inda al-Imam al-Syatibi, 146 
hajjiyyah adalah rukhsah dalam ibadah, dan jual beli salam dalam muamalat. ${ }^{26}$ Terakhir adalah maslahah tahsiniyyah. Maslahah tabsiniyyah ialah pelengkap atau penyempurna dari dua maqashid sebelumnya, meliputi adat kebiasaan dan akhlak mulia. ${ }^{27}$ Salah satu dari maslahah tahsiniyyah adalah larangan membunuh wanita dan anak kecil dalam peperangan.

Kedua, qashdu al-syari' fi wadh'i al-syariah li al-ifham atau maksud Tuhan meletakkan syariat agar dipahami. Maksud dari jenis maqashid ini adalah bahwa Allah menurunkan syariat agar dipahami hamba-Nya. Allah menurukan alQur'an dengan Bahasa Arab, maka yang bisa menjelaskan kepada seluruh umat Islam di dunia adalah orang Arab. Dalam buku Nadhariyyatu al-Maqashidi Inda al-Imam al-Syatibi, Raisuni meringkas lima pokok masalah dalam qashdu al-syari' fi wadh'i al-syariah li al-ifham menjadi dua poin. Poin tersebut ialah syariat ditetapkan dengan Bahasa Arab dan syariat ditetapkan sesuai dengan umat. Maksud dari poin pertama adalah bahwa syariat diturunkan dengan Bahasa Arab, maka untuk memahaminya harus memahami Bahasa Arab. Poin kedua berarti bahwa syariat memahami kondisi umat, maka ia diturunkan sesuai kondisi umat tersebut. ${ }^{28}$

Ketiga, qashdu al-syari' fi wadh'i al-syariah li al-taklif bi muqtadhaha yang berarti maksud Tuhan meletakkan syariat untuk memberi beban / tanggungjawab pada hamba-Nya. Dalam qashdu al-syari' fi wadh'i al-syariah li altaklif bi muqtadhaha, Syatibi menulis dua belas masalah mengenainya, masalah tersebut dapat dipersingkat menjadi dua masalah. ${ }^{29}$ Pertama, al-taklif bima la yuthaqu, pembebanan diluar kemampuan hamba dan kedua, al-taklif bima fibi masyaqqah pembebanan yang mana di dalamnya terdapat kesulitan. Dalam masalah pertama, ${ }^{30}$ Syatibi menjelaskan bahwa Allah memberlakukan syariat pada hamba-Nya yang mampu, jika hamba tersebut tidak mampu menanggungnya, Allah tidak akan membebankan syariat terhadap hamba-Nya. ${ }^{31}$ Kedua, Allah akan meringankan beban bagi hamba-Nya jika dalam taklif terdapat kesulitan. Contohnya seperti rukhsah sholat jama' bagi musafir. ${ }^{32}$

Keempat, qashdu al-syari' fi dukbuli al-mukallaf tabta abkami al-syariah berarti maksud tuhan menugaskan hamba-Nya untuk melaksanakan syariat. Syatibi membahas hal ini ke dalam dua puluh masalah. ${ }^{33}$ Menurut Raisuni,

\footnotetext{
26 Abu Ishaq al-Syatibi, al-Muwafaqat fi Ushuli al-Syariah, 222-223

27 Ahmad Raysuni, Nadhariyyatu al-Maqashidi 'Inda al-Imam al-Syatibi, 146

28 Ahmad Raysuni, Nadhariyyatu al-Maqashidi ..., 149

${ }^{29}$ Moh. Toriquddin, “Teori Maqâshid Syarî'ah Perspektif Al-Syatibi”, 36

30 Ahmad Raysuni, Nadhariyyatu al-Maqashidi Inda al-Imam al-Syatibi, 150

31 Abu Ishaq al-Syatibi, al-Muwafaqat fi Ushuli al-Syariah, 281

32 Abu Ishaq al-Syatibi, al-Muwafaqat ..., 288

33 Moh. Toriquddin, “Teori Maqâshid Syarî'ah Perspektif Al-Syatibi”, 37
} 
pembahasan utama terletak pada masalah kedelapan hingga enam belas. Syatibi menjelaskan bahwa Allah tidak memberlakukan pengeculian bagi hamba-Nya dalam masalah taklif. Semua umat Islam memiliki tanggungan untuk melaksanakan syariat Islam, meskipun tinggal di waktu, tempat dan kondisi yang berbeda. ${ }^{34}$

Setelah dijelaskan hal-hal yang berkenaan dengan qashdu al-syari, bagian ini akan menjelaskan mengenai qashdu al-mukallaf atau tujuan mukallaf. Syatibi menjelaskan dua belas masalah yang terkandung dalam qashdu al-mukallaf. Dalam bagian ini akan dijelaskan tiga dari pada keseluruhan. Masalah pertama, anna ala'mal bi al-niyyat sesungguhnya amal bergantung pada niat. Segala qashdu atau maksud amal mukallaf tergantung pada niatnya. Jika niatnya benar maka amalannya menjadi benar, namun jika berniat batil maka amal tersebut batil juga. Tidak hanya itu ibadah dan riya'-nya seseorang dalam beramal dinilai dari niatnya. Dalam masalah ini, bayi, orang gila, dan tidak sadarkan diri tidak dimasukkan karena mereka tidak bisa berniat dalam amal-amalnya. ${ }^{35}$

Kedua, qashdu al-mukallaf fi al-amal muwafiqan li qashdi al-syari' fi al-tasyri' maksud atau tujuan mukallaf harus sama dengan tujuan Allah. Jika Allah menghendaki tujuan suatu syariat adalah maslahat hamba-Nya secara umum, maka mukallaf harus memiliki tujuan yang sama. Contohnya dalam penjagaan maslahah, seseorang harus menjaga maslahah dirinya sendiri yang termasuk dalam maslahah dharuriyyah. Sebagaimana hadits Rasulullah: "Kau adalah pemimpin dan kau bertanggung jawab atas rakyatnya". Setiap orang memiliki rakyat, paling tidak rakyat seseorang adalah dirinya sendiri, maka ia bertanggung jawab atas dirinya. ${ }^{36}$

Ketiga, man ibtagha fi al-takalifi ma lam tusyra' labu, fa 'amilabu bathilun barang siapa yang mengerjakan sesuatu yang tidak disyariatkan maka itu termasuk batil. Jika seseorang mengerjakan apa yang tidak disyariatkan Allah ia akan berdosa, namun jika hal itu masih sesuai dengan qashdu Allah maka hukumnya boleh. Untuk mengetahui bagaimana mengetahui qashdu Allah dapat dilihat dalam masalah kedelapan. Syatibi menjelaskan jika seseorang melakukan apa yang tidak disyariatkan, maka hendaknya ia melakukan tiga hal berikut; meniatkan amal itu sesuai tujuan Allah yang ia pahami dan niatnya tidak keluar dari ibadah pada Allah semata. Kemudian, berniat bahwa apa yang dikerjakan sesuai dengan qashdu Allah. Langkah terakhir adalah berniat semata-mata hanya untuk mengerjakan perintah Allah. ${ }^{37}$

\footnotetext{
34 Ahmad Raysuni, Nadhariyyatu al-Maqashidi 'Inda al-Imam al-Syatibi, 155

35 Abu Ishaq al-Syatibi, al-Muwafaqat fi Ushuli al-Syariah, 413

36 Abu Ishaq al-Syatibi, al-Muwafaqat ..., 417-418

37 Ahmad Raysuni, Nadhariyyatu al-Maqashidi 'Inda al-Imam al-Syatibi, 164-165
} 


\section{Metode Penentuan Maqashid Menurut Al-Syatibi}

Setiap ulama memiliki metode yang berbeda dalam penentuan maqashid syariah dari suatu hal. Al-Syatibi memiliki empat metode untuk menentukan maqashid syariah. Metode tersebut adalah menganalisa lafadz perintah atau alamr dan lafadz larangan atau al-nahyu, memperhatikan maqashid turunan (at tabi'ah), menganalisa sukut al-syari' dan istigra'.

1. Analisa Lafadz al-Amr dan al-Nabyu

Lafadz al-amr dan al-nahyu menjadi salah satu metode penentuan maqashid karenanya memiliki peranan penting dalam Bahasa Arab. Al-amr dan al-nabyu merupakan dua pembahasan dalam usul lughawi dalam hal permintaan. Al-amr adalah permintaan atas suatu perbuatan dan al-nabyu adalah permintaan untuk meninggalkan suatu perbuatan. Analisa lafadz al-amr dan al-nahyu dilihat dari dua hal yaitu: Mujarrad al amr wa an naby al ibtida'i at tasribi dan memperhatikan konteks illah dari setiap perintah dan larangan. ${ }^{38}$

Mujarrad al amr wa an naby al ibtida'i at tasribi berarti melihat suatu perintah dan larangan dalam dalil secara eksplisit, dan eksistensi keduanya ada secara mandiri (ibtidai i). Contohnya surat al-jumu'ah ayat 9: “...maka segeralah kamu mengingat Allah dan tinggalkanlah jual beli". ${ }^{39}$ Dalam ayat tersebut terlihat jelas terdapat perintah dan larangan di dalamnya tanpa harus menganalisa ayat secara mendalam. Perintah dan larangan yang tertulis adalah perintah untuk segera mengingat Allah (shalat jum'at) dan larang berjualan (saat sholat jum'at). ${ }^{40}$

Sedangkan memperhatikan konteks illah dari setiap perintah dan larangan berarti perintah dan larangan yang ada dalam dalil tidak terlihat secara eksplisit namun harus dipahami lebih mendalam terlebih dahulu. Contohnya seperti dalam dalil mengenai perintah shalat: "dan laksanakanlah shalat, tunaikanlah zakat, dan rukuklah beserta orang yang rukuk". ${ }^{41}$ Perintah yang terlihat secara eksplisit dalam ayat tersebut adalah perintah shalat padahal di dalamnya juga mengandung perintah implisit, yaitu perintah bersuci. Bersuci merupakan illah dari shalat, jika shalat diperintahkan maka bersuci juga diperintahkan meskipun tidak tertulis secara eksplisit dalam dalil. ${ }^{42}$

\section{Memperbatikan Maqashid Turunan (at tabi'ah)}

Maksud dari maqashid turunan atau at tabi'ah adalah maqashid yang muncul turunan dari maqashid awalnya. Contohnya nikah dengan maqashid

\footnotetext{
38 Ahmad Raysuni, Nadhariyyatu al-Maqashidi ..., 296

${ }^{39}$ QS. Al-Jumu'ah: 9

40 Ahmad Raysuni, Nadhariyyatu al-Maqashidi 'Inda al-Imam al-Syatibi, 298

${ }^{41}$ QS. Al-Baqarah: 43

${ }^{42}$ Abu Ishaq al-Syatibi, al-Munafaqat fi Ushuli al-Syariah, 393
} 
awalnya menyambung keturunan, sedangkan maqashid turunan dari nikah adalah berbagi tempat tinggal, saling membantu dalam maslahah dunia dan akhirat, menjaga syahwat dan lain sebagainya. Semua itu adalah maqashid nikah yang disyariatkan Allah. Sebagian maqashid termaktub dalam nash dan sebagian lainnya diambil dari dalil lainnya. ${ }^{43}$

3. Menganalisa sukut al-syari'

Maksud dari menganalisa sukut al-syari' adalah menganalisa hal-hal yang tidak disebutkan atau diterangkan dalam nash oleh al-syari. Jika terdapat perkara yang terjadi namun tidak ada keterangan mengenai hal tersebut tidak serta-merta hal tersebut dikatakan tidak boleh atau tidak dikerjakan karena sesuangguhnya hal inilah yang membuka pintu ijtihad. Ijtihad dapat dilakukan dengan mengidentifikasi maslahah dan mudharat di dalamnya. Jika terkandung maslahah, maka perkara tersebut dapat dilakukan. Sedangkan jika terindikasi adanya mudharat di dalamnya, maka perkara tersebut tidak boleh dilakukan. Pendekatan yang digunakan untuk ijtihad ini adalah pendekatan maslahah mursalah. ${ }^{44}$

\section{Istiqra'}

Syatibi berpendapat bahwa istiqra' merupakan metode yang paling utama untuk mengetahui maqashid syari'ah. ${ }^{45}$ Istiqra' adalah metode induktif yang digunakan untuk menentukan maqashid yang khusus dari yang umum. Jika maqashid khusus bertentangan dengan maqashid umum, maka istiqra' tidak dianggap benar dalam tersebut. ${ }^{46}$ Contoh dari istiqra' adalah bolehnya jual-beli online yang dikhususkan dari dibolehkannya jual-beli dalam qur'an: "Allah telah menghalalkan jual beli dan mengharamkan riba". ${ }^{47}$

\section{Kontribusi al-Syatibi Dalam Kebijakan Fiskal}

Bagi al-Syatibi adanya pemerintahan yang mengatur rakyat merupakan salah satu maslahah dharuri yang harus dipenuhi. Pemerintah diwujudkan guna memenuhi maslahah dunia para rakyatnya. Maslahah akhirat tidak akan terwujud jika maslahah dunia tidak terpenuhi. ${ }^{48}$ Maka dari itu wujud pemerintahan merupakan maslahah dharuri bagi manusia. Segala kebijakan pemerintah juga

${ }^{43}$ Ahmad Raysuni, Nadhariyyatu al-Maqashidi 'Inda al-Imam al-Syatibi, 300

${ }^{44}$ Abu Ishaq al-Syatibi, al-Muwafaqat fi Ushuli al-Syariah, 393a

${ }^{45}$ Maher Hamid al-Hauli, al-Istiqra' wa Daurubu fi Ma'rifati Maqashid al-Syari' 'Inda al-Imam al-Syatibi, (Ghaza: al-Jamiah al-islamiyyah, 2010), 18

${ }^{46}$ Nu'man Jughaim, Thuruq al-Kasyfi 'an Maqashid al-Syari'ab, (Yordania: Dar Alnafaes, 2014), 252

${ }^{47}$ QS. Al-Baqarah: 275

${ }^{48}$ Hammadi al-Ubaidi, al-Syatibi wa Maqashid al-Syari'ah, (Beirut: Dar al-Qutaibah, 1992), 
harus bertujuan maslahah sebagaimana kaidah fiqh tasharrufu al-imam manuthun bi al-maslahah segala macam perbuatan pemimpin harus berlandaskan maslahah rakyatnya. $^{49}$

Guna mempraktekkan maslahah dalam pemerintahan, al-Syatibi memiliki beberapa pemikiran mengenai kebijakan fiskal. Kebijakan fiskal mencakup tiga aspek, yaitu: (1) belanja negara, (2) pajak, dan (3) biaya rumah tangga. ${ }^{50}$ Dalam bagian ini akan dijelaskan mengenai kebijakan fiskal menurut al-Syatibi.

\section{Kebijakan Mengenai Belanja Negara}

Al-Syatibi memiliki pemikiran mengenai asas-asas manajemen belanja negara. Ia berpendapat bahwa manajemen belanja negara harus memenuhi kriteria tertentu. Kriteria tersebut adalah maqashid syariah harus ditegakkan untuk meningkatkan kesejahteraan masyarakat. Maka dari itu, ia berargumen bahwa kepentingan publik terdiri dari tiga kategori, yaitu: primer (dharuriyab), sekunder (hajjiyah), dan pelengkap (tahsiniyah). Secara lebih terperinci, al-Syatibi menjelaskan bahwa belanja negara harus memenuhi kebutuhan primer yang mencakup lima dimensi fungsi. Lima dimensi tersebut adalah fungsi keagamaan (din), fungsi kebutuhan dasar (nafs), fungsi pendidikan ('aql), fungsi ketahanan dan pemberdayaan keluarga (nas), dan fungsi ekonomi (mal). Segenap klasifikasi kebutuhan yang dipaparkan al-Syatibi menunjukkan bahwa manajemen belanja negara bertujuan syari'ah yang focus pada kesejahteraan masyarakat atau kebahagiaan di dunia dan akhirat. ${ }^{51}$

\section{Kebijakan Mengenai Pajak.}

Tidak hanya dalam hal belanja negara, al-Syatibi juga menegakkan maslahah dalam pemungutan pajak. Ia berpendapat bahwa pemungutan pajak harus berasaskan maslahah sebagaimana yang diajarkan oleh pendahulunya, Imam al-Ghazali dan Ibnu al-Farra'. Ia berargumen bahwa kepentingan umum atau maslahah bersama adalah tanggung jawab seluruh lapisan masyarakat. ${ }^{52}$ Untuk mencapai maslahah bersama diperlukan adanya bantuan dari orang yang lebih kepada orang yang membutuhkan, seperti bantuan orang kaya untuk orang miskin. Demi memudahkan dan meratakan distribusi harta, pemerintah dibolehkan untuk membangun baitul mal yang bertugas memungut pajak dari

${ }^{49}$ Abu Hanifah, al-Dar al-Mukbtar, jilid 4, (Beirut: Daar al-Fikr, 1386), 193

${ }^{50}$ Karl E. Case, Principles Of Macroeconomics, 10th ed., (USA: Pearson, 2012), 165

51 Aan Jaelani, "Manajemen pengeluaran publik di Indonesia: Tinjauan ekonomi Islam pada APBN 2017”, MPR A Paper No. 77423, posted 11 March 2017 10:27 UTC, 8

52 Adiwarman Azwar Karim, Sejarab Pemikiran Ekonomi Islam ,(Jakarta: Rajawali Press, 2004), 385-386 
berbagai pihak meskipun pajak belum pernah ada dalam sejarah Islam. ${ }^{53} \mathrm{Hal}$ ini dibolehkan karena pajak semata-mata untuk maslahah umat. Namun jika pajak sudah tidak berlandaskan maslahah bahkan mendzolimi masyarakat, maka pemungutan pajak harus dihentikan.

\section{Kebijakan Mengenai Biaya Rumah Tangga}

Dalam hal biaya rumah tangga, al-Syatibi memiliki pemikiran dalam hal regulasi upah minimum. Ia berpendapat bahwa syariah meliputi aqidah, amaliyah dan juga khuluqiyah. Regulasi upah minimum masuk ke dalam amaliyah yang harus dikerjakan sesuai dengan ajaran Islam. Upah minimum rakyat diregulasi berdasarkan kebutuhan mereka di dunia. Penentuan kebutuhan rakyat tersebut harus sesuai dengan maqashid syariah. ${ }^{54}$

Penentuan kebutuhan manusia dilakukan dengan maqashid syariah karenanya indicator terlengkap untuk kebutuhan. Menurut Maslow, kebutuhan seseorang tidak dapat dipenuhi secara bersamaan namun bertahap sesuai dengan hirarkinya. Maslow memiliki konsep bierarchy of needs yang berarti kebutuhan manusia berjenjang berdasarkan skala prioritasnya. Hirarki tersebut adalah kebutuhan fisiologi, kebutuhan keamanan, kebutuhan sosial, kebutuhan akan penghargaan, dan kebutuhan aktualisasi diri. ${ }^{55}$ Jika dianalisa mendalam, Nampak bahwa hirarki Maslow sepenuhnya telah terkandung dalam maqashid syariah. Bahkan konsep maqashid yang dipaparkan al-Syatibi memiliki keunggulan yaitu meletakkan agama sebagai factor utama dalam elemen kebutuhan. ${ }^{56}$

\section{PENUTUP}

Dalam pembahasannya, Imam al-Syatibi tidak mendenisikan maqashid syariah. Ia langsung membahas kepada pembagian maqashid syariah. Syatibi membagi maqashid menjadi dua, qashdu al-syari' (tujuan Tuhan) dan qashdu almukallaf (tujuan mukallaf). Qashdu al-syari' bertujuan utama maslahah manusia. Syatibi membagi maslahah tersebut menjadi tiga derajat beurutan dari kebutuhan manusia dari padanya, yaitu: dharuriyyah, hajjiyyah, dan tahsiniyyah. Sedangkan untuk metode penentuannya Al-Syatibi memiliki empat metode, yaitu: menganalisa lafadz perintah atau al-amr dan lafadz larangan atau al-nabyu,

${ }^{53}$ Nur Chamid, Jejak Langkah Sejarah Pemikiran Ekonomi Islam, (Yogyakarta: Pustaka Pelajar, 2017), 283

54 Adin Fadilah, "Komponen Kebutuhan Hidup Dalam Regulasi Upah Minimum Perspektif Maqashid”, Al-Shari'ah Muslim Heritage, Vol. 1, No. 1, Mei - Oktober 2016, 25-26

55 James H. Donnelly, et. al. Fundamentals of Management, (New York: Irwin McGraw-Hill, 1998), 270-271 278

56 Boedi Abdullah, Peradaban Pemikiran Ekonomi Islam, (Bandung: Pustaka Setia, 2010), 
memperhatikan maqashid turunan (at tabi'ah), menganalisa sukut al-syari' dan istiqra'.

Maqashid syariah dapat diimplementasikan dalam ketiga aspek kebijakan fiskal, yaitu: belanja negara, pemungutan pajak dan biaya rumah tangga. Manajemen belanja negara harus memenuhi kriteria maqashid syariah guna mencapai kesejahteraan rakyat. Dalam hal pemungutan pajak, pajak dibolehkan semata-mata untuk maslahah umat. Namun jika pajak sudah tidak berlandaskan maslahah bahkan mendzolimi masyarakat, maka pemungutan pajak harus dihentikan. Sedangkan menyangkut biaya rumah tangga, dijelaskan mengenai penetapan upah minimum. Regulasi upah minimum harus didasarkan pada maslahah dharuriyyah yang mengandung lima dimensi. Dimensi keagamaan (din), kebutuhan dasar (nafs), pendidikan ('aq), ketahanan dan pemberdayaan keluarga (nas), dan ekonomi (mal).

\section{DAFTAR PUSTAKA}

Abdullah, Boedi. Peradaban Pemikiran Ekonomi Islam, Bandung: Pustaka Setia, 2010.

Abu Hanifah, al-Dar al-Mukhtar, jilid 4, Beirut: Daar al-Fikr, 1386.

Al-Hauli, Maher Hamid. al-Istiqra' wa Daurubu fi Ma'rifati Maqashid al-Syari' Inda al-Imam al-Syatibi, Ghaza: al-Jamiah al-islamiyyah, 2010.

Al-Syatibi, Abu Ishaq. al-Muwafaqat fi Ushuli al-Syariah, Beirut: Dar Al-Kotob AlIlmiyah, 2004.

Al-Tanbakti, Ahmad Baba. Nailu al-Ibtihaj bi Tathridzi al-Dibaj, Tripoli: Daar alKatib, 2000.

Al-Ubaidi, Hammadi. al-Syatibi wa Maqashid al-Syari'ah, Beirut: Dar al-Qutaibah, 1992.

Al-Yubi, Muhammad Saad bin Ahmad bin Mas'ud. Maqashidu al-Syariah alIslamiyah wa 'Alaqatuha bi al-Adillati al-Syariyyah, Riyadh: Daar al-Hijrah, 1998.

Aminah. "Maqāṣid Asy-Syarī'Ah Pengertian Dan Penerapan Dalam Ekonomi Islam", Fitrah Jurnal Kajian Ilmu-ilmu Keislaman, Vol. 03 No. 1 Juni (2017).

Case, Karl E. Principles Of Macroeconomics, 10th ed., USA: Pearson, 2012.

Chamid, Nur. Jejak Langkah Sejarah Pemikiran Ekonomi Islam, Yogyakarta: Pustaka Pelajar, 2017. 
Djalaluddin, Muhammad Mawardi. "Pemikiran Abu Ishaq Al-Syatibi dalam Kitab Al-Muwafaqat”, Al Daulah Vol. 4 / No. 2 / Desember (2015).

Donnelly, James H. et. al. Fundamentals of Management, New York: Irwin McGraw-Hill, 1998.

Fadilah, Adin. "Komponen Kebutuhan Hidup Dalam Regulasi Upah Minimum Perspektif Maqashid”, Al-Shari'ah Muslim Heritage, Vol. 1, No. 1, Mei Oktober (2016).

https://id.tradingeconomics.com/country-list/gdp-per-capita

Imam al-Shatibi: The Master Architect of Maqasid, http://www.iais.org.my/e/attach/Imam_al-Shatibi.pdf, diakses pada tanggal 25 Juli 2018, 11.41 WIB, p. 2

Iskandar, Kamil. Al-Munjid Al Wasith, Beirut:Daar al-Masyriq.

Jaelani, Aan. "Manajemen pengeluaran publik di Indonesia: Tinjauan ekonomi Islam pada APBN 2017”, MPRA Paper No. 77423, posted 11 March 2017 10:27 UTC.

Jughaim, Nu'man. Thuruq al-Kasyfi 'an Maqashid al-Syari'ah, Yordania: Dar Alnafaes, 2014.

Kara, Muslimin. "Pemikiran Al-Syatibi Tentang Maslahah Dan Implementasinya Dalam Pengembangan Ekonomi Syariah", Assets Volume 2 Nomor 2 (2012).

Karim, Adiwarman Azwar. Sejarah Pemikiran Ekonomi Islam, Jakarta: Rajawali Press, 2004.

Mas'ud, M. Khalid. "Abu Ishaq Shatibi: His Life and Works", Islamic Studies Vol. 14, No. 2 (Summer 1975)

Nor, Radieah Mohd. "Success Factors for Baitul mal Management during the Reign of Caliph Umar ibn Abdul Aziz". Open Journal of Social Sciences, Vol.03 No.05 (2015).

Raysuni, Ahmad. Nadhariyyatu al-Maqashidi Inda al-Imam al-Syatibi, Virginia: IIIT, 1995.

Rosyadi, Imron. "Pemikiran Asy-Syatibi Tentang Maslahah Mursalah", Profetika, Jurnal Studi Islam, Vol. 14, No. 1, Juni (2013).

Sugiono. Metode Penelitian Kuantitatif, Kualitatif Dan R \& D, Bandung: Alfabeta, 2014.

Toriquddin, Moh. “Teori Maqâshid Syarî’ah Perspektif Al-Syatibi”, De Jure, Jurnal Syariah dan Hukum, Volume 6 Nomor 1, Juni (2014). 